BRK Global Healthcare Journal, 978-1-5323-4858-7 Volume

3, Issue 1, 2019

\title{
African American Women and Domestic Violence: Addressing their Voice of Silence
}

\author{
Bernice Roberts Kennedy, PhD, APRN, PMN-CNS, BC \\ Research Consultant \\ Chalice C. Rhodes (Former Jenkins), PhD, LPC, NCC \\ Director of Behavioral Health Counseling \\ Assistant Clinical Professor in the Department of Counseling \& Family \\ Therapy \\ College of Nursing and Health Professionals, Drexel University
}

Correspondences Address:

BRK Global Healthcare Consulting Firm, LLC P.O

90899

Columbia, South Carolina, 29209 e-

mail brkhealthcare@gmail.com

Ain't I A Woman?

Speech by Sojourner Truth, 1851

Women's Rights Convention in Akron, Ofio. 
That man over there says that women need to be helped into carriages, and lifted over ditches, and to have the best place everywhere. Nobody ever helps me into carriages, or over mudpuddles, or gives me any best place! And ain't I a woman? Look at me! Look at my arm! I have ploughed and planted, and gathered into barns, and no man could head me! And ain't I a woman? I could work as much and eat as much as a man - when I could get it - and bear the lash as well! And ain't I a woman? I have borne five children, and seen most all sold off to slavery, and when I cried out with my mother's grief, none but Jesus heard me! And ain't I a woman? 


\begin{abstract}
Historically, during slavery, the international slave trade promoted normalization of violence against African American women. During slavery, African American women endured inhuman conditions because of the majority race views of them as being over-sexualized, physically strong, and immoral. This perception of the African American women as being highly sexual and more sexual than white women results in slave owner justifying their sexual violation and degrading of the African American women. The stereotypical representations of African American women as strong, controlling, dangerous, fearless, and invulnerable may interfere with the African American women receiving the needed services for domestic violence in the community. The Strong Black Women Archetype has been dated back to slavery describing their coping mechanism in dealing with oppression by developing a strong, less traditionally female role. The authors developed a model: The Multidimensional Perspectives of Factors Contributing to Domestic Violence of African American Women in the United States. This model depicts historically, the factors contributing to domestic violence of African American women in the United States. Also, this model addressed the African American women subscribing to the Strong Black Women Archetype to cope with domestic violence. Despite the increase in domestic violence in African American women, they focused more on the issue of racism instead of sexism in America. African American women have experienced the two obstacles of racism and sexism in America. However, African American women and men believe racism is more critical than sexism. Therefore, domestic violence in the African American population may remain silent because of cultural loyalty. However, the voice of silence of African American females is gradually changing with the upcoming generations.
\end{abstract}

Copyright BRK Global Healthcare Journal, 2018, 978-1-5323-4858-7; http://brkhealthcare.com/brk-healthcare-journal/; doi:10.35455/brk12345678

Key Words: African American, females; domestic violence; intimate partner violence; strong black women archetype; the voice of silence. 


\section{Introduction}

Approximately, 1.3 million American women experience domestic violence/intimate partner violence (Jones, 2014). Women consist of $85 \%$ of the victims of domestic violence/intimate partner violence (Jones, 2014). However, most of these cases are not reported to the legal systems.

African American women experience more physical violence from an intimate partner during their lifetime than other women (Green, 2017; Kennedy, 2015). More than 4 in 10 African American women experience domestic violence (Green, 2017). They experience higher rates of psychological abuse including humiliation, insults, name-calling, and coercive control than other women (Green, 2017; Kennedy, 2015). African American women experience more sexual violence at a higher rate than other women. Approximately, $20 \%$ of African American women are raped during their lifetimes in comparison to other women (Green, 2017). African American women are more likely to be murdered by a partner compared to White women.

African American women experience disproportionate violence in the home, school, on the job and their neighborhoods (Green, 2017). They experience high rates of intimate partner violence rape, and homicide. African American women and girls experience institutionalized racism such as being punished in school and entering the criminal justice system after surviving physical or sexual abuse (Green, 2017). They are subject to racial profiling and police brutality and incarcerated at high rates.

Historically, the silence that African American women endured for centuries has been practiced out of necessity for their survival because of the lack of legal protection for slaves in general especially the female slave (Brousard, 2013). This practice of silence has been passed down from generation to generation.

The authors developed a model: The Multidimensional Model of Factors Contributing to Domestic Violence of African American Women in the United States. This model depicts historically, the factors contributing to domestic violence in African American women. In the model, Causal Conditions of Social Inequalities display the domestic violence in African American women such as legal and criminal issues, trends in domestic violence in African

American women, intervening conditions, and treatment strategies. These factors are multidimensional; therefore, they must be addressed from different perspectives. Figure 1: The Multidimensional Model of Factors Contributing to Domestic Violence of African American Women in the United States is displayed below: 


\section{Figure 1: The Multidimensional Model of Factors Contributing to Domestic Violence of African American Women in the United}

\section{States}

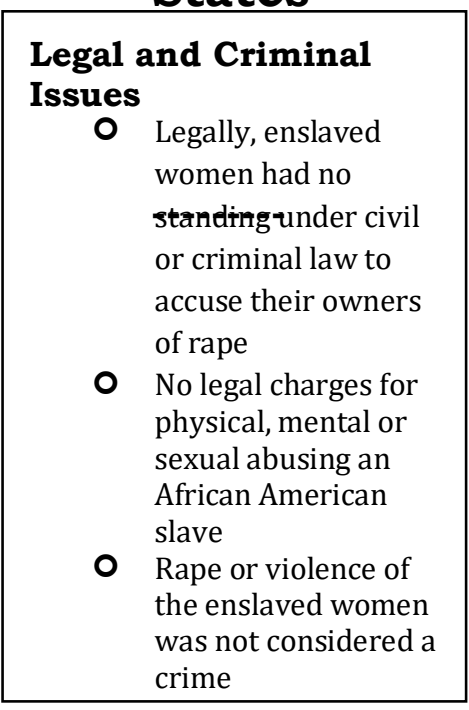

\section{Causal Conditions Social Inequalities \\ O Historical Perspective of Slavery \\ - Enslaved women considered livestock and not human being \\ - Enslaved women worked as hard as the enslaved men and took care of her family.}

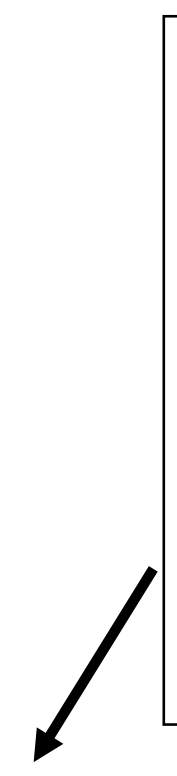

Legal and Criminal Issues

O Less likely to report abuse (culture loyalty)

- Legal system views the African American women just as aggressive as the man/Increase risk of legal charges

- More likely to return to abuser/Increase risk of being abused

- Shelters were less likely to receive African Americans females / image of fearless image of fearless

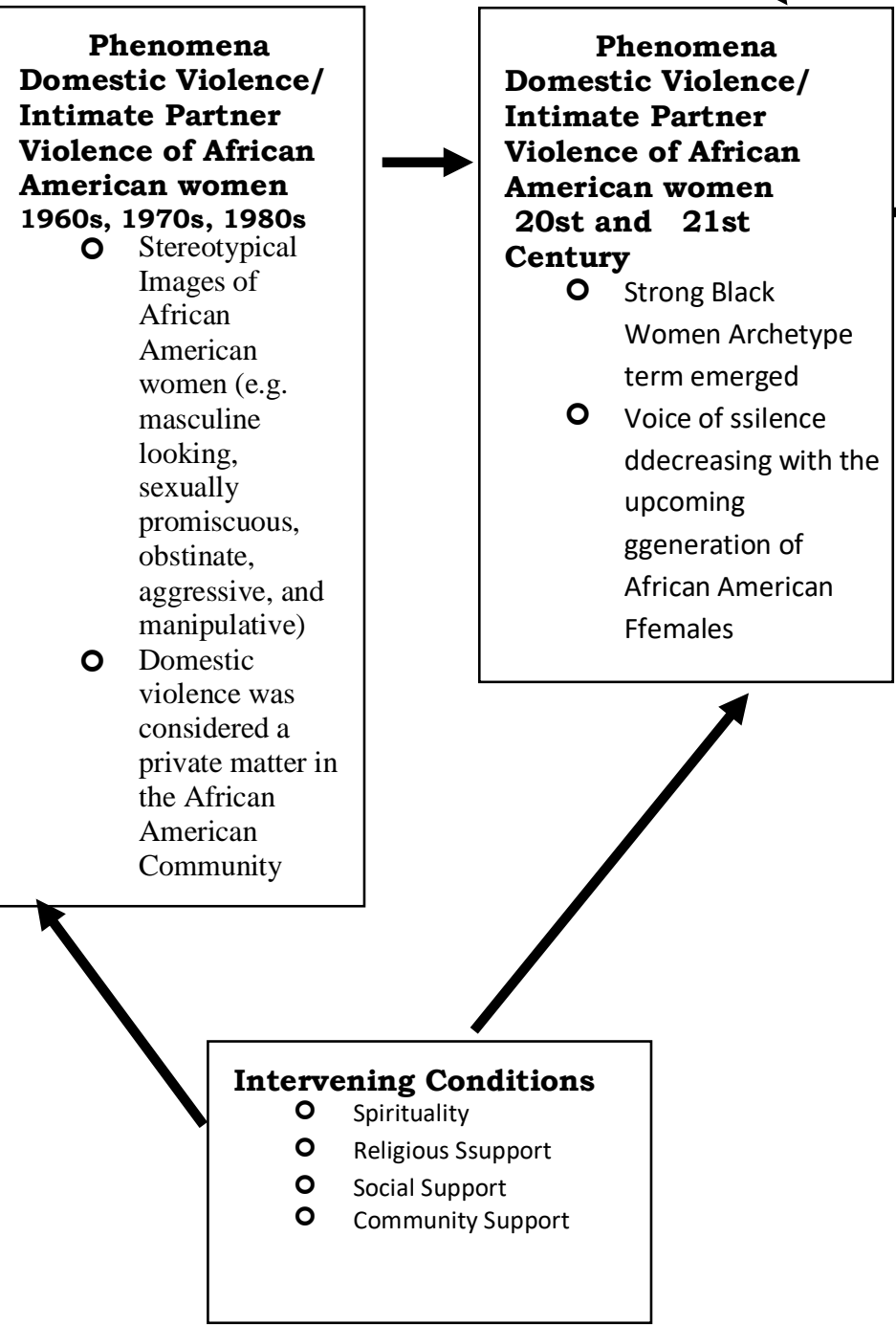

Treatment and Strategies

Consequences

Negative Outcomes

O Strong Black

Women

Archetype

increase

Ineffective coping

(voice of silent)

and endure the

violence

O Increased

depression after

leaving domestic

violence

relationship

o Remain in

domestic violence relationship

based on cultural and religious

belief, etc.

- Poor health

outcomes (e.g.,

stress,

depression.,

mental health

problems, etc.)

based on

ineffective coping

with stressors

Positive Outcomes

O Spiritualty and religion assisted

survivors in

dealing with

depression and

stress

- Resilience in coping with stress of domestic violence

- Increase Empowerment with participating in open forums.

- Advocacy groups for policy development and changing laws 
African American women experience sexual assaults and domestic/intimate partner violence at a disproportionate rate and higher rates of interracial violence than other ethnic groups (Jones, 2014; Kennedy, 2015). They have a strong sense of cultural loyalty to the race that renders them to remain silent about their domestic violence/intimate violence. They are hesitated to call racially biases police who may harm them more. Also, African American women may believe the lack of loyalty to the community or race when airing their personal problems in front of White people. Despite the increase in domestic violence in African American women, they focused more on the issue of racism instead of sexism in America (Jones, 2014; Kennedy, 2015). Although, African American women have experienced the two obstacles of racism and sexism in America; however, African American women and men believe racism is more critical than sexism. Therefore, domestic violence in the African America population may remain silent. The next section will discuss the historical perspective, stereotypical representations of African American women, the Strong Black Woman (SBWA) Archetype, legal and criminal issues, and treatment issues and strategies.

\section{Historical Perspective}

Historically, African American family in Africa was strong and powerful with a religious and political background that exerted great influence as a center of African civilization (Feagin \& Sikes, 1994; Kennedy, 2007; Kennedy, 2015; Kennedy, 2017; McCollum, 1997). The father was considered the head of the family and the bloodline and the heritage of the men was considered the provider and protector of the family (Feagin, \& Sikes, 1994; Kennedy, 2007; Kennedy, 2015; Kennedy, 2017; McCollum, 1997). Slavery and victimization of the dominant culture have caused the African American man's role in the family to be obscured. Therefore, slavery has positioned the African American man in a subservient and dependent role while fostering the domination of the women.

The role of the patriarchy of the African American male is seldom found in the African American male (Kennedy, 2007; Kennedy, 2015). However, the African American father's identity is tied to their ability to provide for their family regardless of their incomes. Conflict may arise in the family system when he demands recognition but unable to provide for the family because of the lack of financial resources (Kennedy, 2007; Kennedy, 2015). African American men have limited success in fulfilling the provider role and head of the household. The effects of racism and discrimination have resulted in poverty with low income and other societal forces placing the African American male in a powerless position threatening their husband-father role in the African American families. 
Historically, during slavery, the international slave trade promoted normalization of violence against African American women (Kennedy, 2007; Kennedy, 2015; West 2004). The International slave trade resulted in illegal, rape, and force breeding to increase the slave population. Rather than acknowledge this as sexual victimization, slave owners portrayed enslaved women as promiscuous, immoral Jezebel who seduced their masters. During this period, there was no legal sanction against raping African American women. Today, these stereotypes have contributed to African American women's belief about being less credible rape victims. During slavery, African American women endured inhuman conditions because of the majority race views of them as being over-sexualized, physically strong, and immoral (Beauboboeuf-Lafontant, 2009; Thomas, Witherspoon, \& Speight, 2004). This perception of the African American women as being highly sexual and more sexual than white women results in slave owner justifying their sexual violation and degrading of the African American women (Harris-Lacewell, 2001). These women not only were subjected to sexual abuse and physical abuse by slave masters but expected to perform the same work as the African American men. The enslaved African American women were subjected to dual brutality (Woods Giscombe, 2010). The female slaves were held to the same rigorous labor standards as the enslaved men with the additional responsibility of caring for their families and children. Slaves were required to provide rigorous labor, against their will with abuse and even death (Woods-Giscombe, 2010). Also, slaves did not receive compensation, worked in dangerous, unsanitary conditions with increased risk for devoting injuries. The enslaved African American women did not have a space to express her pain and anger resulting in building an emotional mask to shield these emotions from their slave masters (Black \& Peacock, 2011). The hiding of these emotions served as a coping mechanism in dealing with oppression and abuse of African American women.

Historically, during the antebellum period, African American women were victims of rape by both white and black men who raped enslaved African American females working in the fields and household of plantations (Collin, 2000; Kennedy, 2007; Kennedy, 2017; West, 2004). However, African American women continued to experience sexual abuse and harassment after the emancipation because of employment discrimination in lower-paying domestic servants' jobs. Slavery was an economic advantage for Europeans; however, Africans came without their families, in chains, involuntarily, and deplorable traveling conditions. African Americans have experienced social inequalities in the United States. Social inequalities resulted in structure violence in our society. African Americans were not allowed to assimilate into the new culture as other immigrants in the United States (McCollum, 1997: Kennedy, 2007; Kennedy, 2015). However, slavery has ended, the results of slavery are very prominent today. African Americans continue to 
experience racism, discrimination, unemployment, etc. (Kennedy, 2007; Kennedy, 2015; Kennedy, 2017; McCollum, 1997).

The African American community has been forced into a matriarchal structure instead of a patriarchal structure because of the role of the African American women shifted for the survival of the black family. Staples (1985) explained that the matriarchal image of the African American woman surfaced out of the necessary role shift of the African American family.

During the 1960s and 1970s, the stereotype image of African American women as a matriarch and taking power over the African American man became more prevalent in society (Kennedy, 2015). African American women began to assume more visible leadership roles during this time in American organizations further contributing to domestic violence. Domestic violence was not discussed in the African American community until the 1980s. Therefore, domestic violence was more of a private matter in the African American community.

Slavery placed division and destruction of the family unit of the enslaved African American families (Woods-Giscombe, 2010). The permanent loss of family members especially children was the consequence of slavery. Often, infants were taken out of their mothers' hands after birth and sold to another plantation. The female slaves were powerless over their own body to include sexual violence by her slave masters, reproductive violence, and treatment as human guinea pigs for gynecological medical experimentations (Woods-Giscombe, 2010). The male slaves were powerless to protect wives and children; therefore, the female slaves were responsible for their own survival (Woods-Giscombe, 2010). It is suggested that this self-protective, independence nature of the African American women is an adaptive coping response derived from African American women's need to be self-sufficient during slavery.

For the African American women, there was not just injustice, they would receive negative consequences for revealing the abuse (Kennedy, 2015). However, African American women dealt with sexual victimization by running away, fought back, engage in activism, and develop a culture of silent (Brousard, 2013). Legally, the enslaved women had no standing under civil or criminal law to accuse their owners of rape. The silence of African American women experienced emerged because of (a) the silence from slavery and their status; (b) silence of the legal system ignoring them, and (c) the failure of society today to tell her story (Brousard, 2013).

\section{Stereotypical Representations of African Women}

The stereotypical representations of African American women as strong, controlling, dangerous, fearless, and invulnerable may interfere with the African American women receiving the needed services for domestic violence in the community (Bell \& Mattis, 2000). As indicated in the Multidimensional Model of Factors Contributing to Domestic Violence of African American 
Women in the United States, it is believed that these stereotypical images of African American women contributed to their domestic violence and inability to seek community resources. African American women and scholars have reported stereotype views of African American women as being aggressive, domineering, castrating, independent, sexually promiscuous, and money- hungry (Davis, 2016; Gooden, 1980; Hannerz, 1969). These perceptions contributed to treating African American women like men to include hitting women (Gooden, 1980; Hannerz, 1969). Furthermore, these negative representations of the African American women may lead some African American men to rationalize that violence is required to control women who are perceived to be physically dangerous and capable of taking away a man's manhood (Bell \& Mattis, 2000; Davis, 2016; Kennedy, 2015). The hiding of these emotions served as a coping mechanism in dealing with oppression and abuse of African American women.

Bell and Mattis (2000) shed light of these stereotype views of the African American women:

"Women whose physical and psychological makeup makes them as "other" for example, those who are dark complexionate, tall, overweight, verbally assertive, drug dependent, mentally ill, and/or women who chose to fight back- are often treated as if they are responsible and/or deserving of the abuse that they experience. They are perceived as "inauthentic victims" (p.520).

In the United States, the image of women has been considered Victorian of gentility, femininity, and vulnerability, however, African American womanhood has been more construed as unnatural, superwomen, grotesquely antifeminist, destructive, and overpowering (Bell \& Mattis, 2000). These misrepresentations of the African American women's image have been considered contributing factors for domestic violence by some social scientists (Bell \& Mattis, 2000). Clergies, ministries, health and human services professionals, criminal justice, educational institutions, and legal system must be aware of these issues regarding these stereotypical presentations of African American women and females in their services to better assist them with the needed services.

African American women are more likely to be killed by a partner or be killed because of domestic violence (Bent-Goodley, 2004). Also, African American women have been denied housing to shelter based on appearing fearless, being too strong, hardened, tough, back-talking, strong, permissive, and undeserving of protection. Lack of cultural competence treatment may result because of these stereotypical views of African American women (Bent-Goodley, 2004). 


\section{Negative Representations of African American Women}

Willis (1989) proposed that when the African American male meets the African American female, he sees someone whom he has been told is dominant in the family, a castrating Black woman (i.e., the matriarch). He argued that African American males and females have been programmed from an early age, by society, to be destructive of each other. Also, Willis (1989) contends that such negative attitudes have their origins in the American slavery era and have been passed from generation to generation. As a result, mate selection in the African American community is predicated on negative stereotypes, which increases the likelihood of problems in the relationship.

Scholars have identified 4 stereotype images for female African Americans, the Mammy, Aunt Jemimah, Sapphire, and Jezebelle (Green, 1999; Jewell, 1993; Woods-Giscombé, 2010). The origin of these stereotypes originated in the South but later permeated in all regions. The most enduring of these images is the Mammy which originated during slavery (Green, 1999; Jewell, 1993). The mammy was often seen as opposite from the European standard of beauty with masculine features, obese, and matronly figure. The Aunt Jemimah emerged out of the Mammy image which was restricted to cooking. However, Aunt Jemimah 's duties were more domestic work. The Sapphire has similar emotional characteristics of Mammy and Aunt Jemimah but fiercer, independence and cantankerous in her role of matriarch. Often, the Sapphire is viewed as woman who dominate her husband or the Angry Black Woman. The Jezebelle is viewed as a harlot or "bad Black girl." This traditional image of the Jezebelle is light-skinned, slender Mulatto, and straight hair. Currently, the Superwomen image developed to counteract negative societal characterization of African American womanhood (e.g., Mammy, Jezebel, and Welfare Queen) (Woods-Giscombé, 2010).

Collins (2000) identified stereotypes of African American women (e.g., mammies, matriarchs, jezebels, and welfare mothers) as controlling images that cause African American men to objectify African American women. Also, Collins (2000) contended that these images, created by White Americans during the slave era and beyond, have served to control and oppress African American women and reflect the dominant group's interest in maintaining Black women's subordination.

Gillum (2002) in a study found that American men's beliefs in the matriarch and jezebel stereotypes were positively related to their belief in the justification of intimate partner violence against African American women. Cultural factors contribute to intimate partner violence in African American families because of societal tolerance for violence against Blacks in this country, as well as the myth that violence is acceptable and condoned part of Black culture, Black family 
life, and African American communities. Because of the intergeneration of their exposure to racism, some African Americans have accepted these negative representations of African American man and women.

\section{The Strong Black Woman (SBWA) Archetype}

The Strong Black Woman (SBWA) Archetype is a culture model that describes the norms for the African American women for thinking, feeling and behaving as rooted in their historical experience in Africa (Abrams, Maxwell, Pope, \& Belgrave, 2014; Beauboeuf-Lafontant, 2009; Woods, 2013). Historically, African American women maintain a consistent manifestation of strength while suppressing emotion, masking difficulties, and abiding by cultural mandate of silence. The SBWA has been dated back to slavery describing their coping mechanism in dealing with oppression by developing in a strong, less traditionally female role (Watson \& Hunter, 2015). However, this term of SBWA was not mentioned until the $20^{\text {th }}$ century. Scholars traced that this SBWA originated from slavery and permanented from generation to generation. African American women continue to experience challenges such as financial hardship, primary caregiving responsibilities, racism, and sexism.

SBWA portrays African Americans as nurturing, resilient and resistant to being dependent on or vulnerable to psychological or physical challenges (Woods, 2013). This model has been used as a cognitive framework in guiding African American women in structuring and formatting experiences in their lives.

Historically, African American women had numerous challenges associated with various struggles, forms of oppression and negative character stereotypes (Watson \& Hunter, 2015). These character stereotypes impacted African American women's social well-being.

Today, African American women continue to take pride in being superwomen to resist against the intersectionality of being both black and female in society. African American women are praised for their resilience and strengths in holding her family together, working harder than others, and keeping her house (Baker et al., 2015). However, African American women experience tensions in maintaining this superwomen image.

Often, African American women who subscribed to the SBWA internalize stress to maintain self-reliance and not seek social support from others (Watson-Singleton, 2017).

These women often do not seek assistance from others because of the conscious pressure to remain strong. The lack of social support contributes to extreme stress impacting on their physical and psychological well-being (Kennedy, 2017; Watson-Singleton, 2017)

African Americans are often more prone to experience psychological stress in comparison to White Americans (Barnes, 2017). African American women who subscribed to the SBWA 
experience mental health problems to include reporting higher levels of sadness, hopelessness, worthlessness to take care of everyone's health and neglecting their own health (Barnes ,2017). Often, African American women don't prioritize their self-care and seek self-nourishment, social support, and psychological help because this approach of seeking assistance could be perceived as a weakness (Barnes, 2017; Watson \& Hunter, 2016; Kennedy, 2017).

Historically, in African American women, slavery has affected the ways they are viewed by society and other African Americans (Woods- Giscombé. 2010). Post enslavement contributed to more environmental stress in diverse forums of society contributing to cultural oppression to the African American women and her family (Woods- Giscombé. 2010). The perception of African Americans was strong during slavery maintain the idea during post-slavery that African American women were ideal for domestic servants for white women (Woods- Giscombé. 2010). The SBWA is an image of the African American women in the United States, pressuring her to maintain this image of strength always. Because the ideal of strength is internalized highly among African American women, they socialize others to habituate behavior reflecting strength (WoodsGiscombé. 2010).

\section{Legal and Criminal Issues}

During slavery, the rape of Black women was not considered a crime and litigated if prosecuted because of "property crime" with their owners (Davis, 1998; Kennedy, 2007). The enslaved women were considered livestock, not a human being. Legally, the enslaved African American women had no standing under civil or criminal law to accuse the owners of rape. The rape or violence of the enslaved African American women was not considered a crime. Today, African Americans continue to experience disparate treatment from various groups such as police, sexual assaults advocates, medical personnel, and the court system (Campbell, Wasco, Ahrens, Sefl, \& Barnes, 2001).

Currently, these sexual stereotype views of slavery regarding African American women remain today (Abrams et al., 2014; Beauboeuf-Lafontant, 2009; Watson \& Hunter, 2015; Woods, 2013). African American women are depicted as sexually insatiable, promiscuous, and morally corrupt which was used to justify the sexual exploitation during and after slavery. These stereotypical representations of African American women are believed to be contributing factors of others viewing them in a sexual manner.

African American women are less likely to press charges against perpetrators because of their lack of trust in the criminal justice system (Wyckoff \& Simpson, 2008). In addition, African American women may not seek outside interventions because of the separate mindset that whites do not need to be in their business. Often, they will seek solutions within the community and avoid 
the criminal justice system that stereotypes African American males as being dangerous (Wyckoff \& Simpson, 2008). African American women are less likely than white women to report being rape to others (Lee, Thompson, \& Mechanic, 2002). When a woman is murdered, the perpetrator is (5 times) more likely to be a spouse or an intimate partner than to be a stranger (Lee et al., 2002). While IPV homicide rates have declined during the past 20 years, the rate for African American women is more than double that observed for white women (Lee et al., 2002). Women are (5 times) more likely to be murdered by a spouse or intimate partner than a stranger (Lee et al., 2002).

African American women reports of IV homicide rates are more than double that of white women (Lee et al., 2002). Approximately, (40\%) of African American women reported coercive contact of sexual nature by the age of 18 (“Africana Voices against Violence, 2002”). The number one killer of African American females (15 to 34) is homicide by a current or former intimate partner (“Africana Voices against Violence, 2002”). In a study of African American sexual survivors, only (17\%) of participants reported the assault to law enforcement ("Africana Voices against Violence, 2002").

African American women are more likely to leave their abusers, return to the abusive relationship, and endure the abuse longer (Ramos, Carlson, \& McNutt, 2004). However, in some situations when a woman leaves the abusive relationship and returns places her at a higher risk for injuries and death. Also, the longer she stays in an abusive relationship places her at a risk for mental health problems (Ramos et al., 2004). In addition, African American women are more prone to fight back in an abusive relationship which places her in a position of injury to include death (Ramos et al., 2004).

Racial/ethnic communities have different cultural norms regarding intimate partner roles, the acceptability of intimate partner violence (IPV), the importance of the family as an intact unit, and the appropriateness of seeking community services (Kennedy, 2007; Lee et al., 2002). The victim's response to abuse is based on their beliefs and expectations about the impact of those choices on women, her children, and the community (Lee et al., 2002).

Only half of women who experience IVP sought care for the injury (Lee et al., 2002). African Americans and Native Americans have reported more experience of severe injuries with weapons used against them (Lee et al., 2002). White women are more likely than other ethnic groups to seek legal consultation from a lawyer regarding violence or abuse than African American women (Lee et al., 2002).

When African American women called the legal system for protection, they are more likely to be blamed for being equally aggressive, whereas the police action would rarely result in the arrest of their perpetrators (Wyckoff \& Simpson, 2008). Because of the racial stereotypes with 
community pressure of silence, the unresponsiveness of the criminal justice system continues to increase the likelihood of African American women fighting back and taking the matter in their own hands (Wyckoff \& Simpson, 2008).

\section{Intervening Conditions}

In this model, intervention conditions for the African American women consist of (a) spirituality, (b) religious support, (c) social support, and community support. These concepts have an impact on the domestic violence outcomes of African American women.

African American's primary roots have originated from West Africa which has reflected some of their cultural traditions and patterns common to West Africans such as a strong family network and belief in spirituality (Kennedy, Mathis \& Woods, 2007; Kennedy, 2015). They perceive health as a dynamic process of the mind, body, and spirit (Amankwaa 2003).

To effectively meet the needs of most African American families, the integration of religion and spirituality is necessary (Billingsley 1999; Dana 2002; Kennedy, 2015; Tidwell 2004). African American cultural heritage has been centered on religion and spirituality with the church as an important source of social support (Billingsley 1999; Dana 2002; Kennedy, 2015; Tidwell 2004).

Historically, African Americans use collectivism, communalism Interconnectedness, and spirituality in their relationships with others in the community (Bent-Goodley, 2005). The African American families emphasized on collectivity. The African American culture, overall, places a strong value on collective decision-making. In collectivist cultures, people value "community," as a good, and they believe in honoring members of their immediate community, especially the family. This principle promotes the significance of the extended family and the larger community in the development of African American families and individuals (Bent-Goodley, 2005).

The help-seeking behavior of African Americans is influenced by essential factors such as social support, spirituality, and coping (Bradley, Schwartz, \& Kaslow, 2005). Often, African American women who prescribe to the SBWA internalize stress to maintain self-reliance and not seek social support from others (Watson-Singleton, 2017). These women often do not seek assistance or support from others because of the conscious pressure to remain strong. The lack of social support contributes to extreme stress impacting on their physical and psychological wellbeing (Kennedy, 2017; Watson-Singleton, 2017). However, African American women with this SBWA may seek social support through religious and spiritual involvement.

The intervening intervention will impact on the health outcomes of African American Women and domestic violence. The next section will address Treatment and Strategies/Consequences. 


\section{Treatment and Strategies/Consequences}

African American middle-class women were more likely to experience domestic violence than white middle-class women (Bent-Goodley, 2004). Although, there have been limited research studies to explain the effect of socioeconomic status and domestic violence. However, BentGoodley (2004) suggested that there is the perpetuation of domestic violence in the African American community such as inaccessibility of services, lack of cultural competence among service providers, racial loyalty, and gender entrapment. The United States system and services are based on European views and often not culturally sensitive to the unique cultural, norms, and values of the diverse ethnic groups. African American women are often viewed with negative stereotype views or myths when entering healthcare, social services, and criminal justice systems. Another barrier in seeking assistance for domestic violence is racial loyalty whereas she withstands this abuse and self-sacrifice for loyalty to her community sacrificing her physical, psychological, and spiritual well-being.

Often, African American women are hesitated to report domestic violence for fear of discrimination and because of the injustice of African American men often experience in the criminal justice system (Bent-Goodley, 2004; Jenkins \& Kennedy, 2013). African American women are fearful of various forms of criminal injustice which may increase their chances of physical and mental abuse (Bent-Goodley, 2004). Thereby, she is often expected to sustain the abuse to protect the family, maintain the relationship, and spare the large community of embarrassment sacrificing her safety (Bent-Goodley, 2004). African American women often don't seek treatment or services because of contextual factors to include the potential for retaliation by the abuser, available economic resources, and the potential for child abuse, personal emotional strengths, and perception of available social support (Lee et al., 2002).

African American women often outnumber African American men because of the premature death and disproportionate incarceration of African American males (Lane et al., 2004). It is believed that the lack of males decreases the African American women's bargaining power in forming relationships resulting in the number of women involved with a man who has two or more sexual partners simultaneously (Lane et al., 2004). Therefore, women would tolerate abuse in relationships when their options are limited. Often, African American women may deny their experience of abuse to protect their partner (Bent-Goodley, 2004). They may place themselves at risk of physical harm not allowing the partner to be held accountable for their behavior (BentGoodley, 2004).

African American women often view the cause of family violence are because men are angry or aggressive in response to racism resulting from his struggle to maintain an economically social 
role in mainstream American (Daly, Jennings, Beckett, \& Leashore, 1995). African American males are an endangered species and some men blame the African American women for the adversities experienced by men (Bell \& Mattis,2000). Often, abusive men abdicate responsibilities for their personal choice and behavior thereby blaming the women for the violence inflicted on them.

African American women may be convinced by community members, friends, family and/or abusive partners that African American men are at particular risk and the African American females have a particular responsibility for their protection (Bell \& Mattis,2000; Kennedy, 2013). Many African American women who are being battered or abused by partner or son may not report this abuse because they would be contributing to the victimization of their African American males (Bell \& Mattis,2000; Kennedy, 2013).

\section{Mental Health Problems}

African American female survivors of intimate partner violence frequently experience psychological distress as evidence of depression, anxiety, stress, and somatic complaints (Kennedy, 2007; West, 2004). The emotional and psychological abuses inflicted by batters are more likely to have a long-time effect. Approximately, (60\%) of battered women have reported depression (Barnett, 2000). Battered women have a higher risk of suicide. The battered African American women have (50\%) reports of suicide in comparison to Caucasian women (25\%) reports (Fischbach, \& Herbert, 1997).

Posttraumatic Stress Disorder (PTSD) is characterized by symptoms such as flashbacks, intrusive imagery, nightmares, anxiety, emotional numbing, insomnia, hyper-vigilance, and avoidance of traumatic triggers (Kennedy, 2007). Victims may develop psychosocial, emotional, and behavioral difficulties after experiencing physical abuse in the context of domestic violence or witnessing parental abuse (Kennedy, 2007).

Victims who experienced multiple types of abuse were at an increased risk of mental health symptoms (Caetano \&, Cunradi, 2003). Physical and emotional intimate partner violence incidents were related to depressive symptoms, PTSD symptoms, and suicidality. In a study by Caetano and Cunradi, (2003), (31\%) of African America women were more depressed in comparison to (14\%) of white women. Physical and non-physical intimate partner violence among African American women was related to suicide attempts (Kaslow et al., 2000).

Depression is the most common mental health problem in survivals of sexual assaults and partner abuse (Huang \& Gunn, 2001; Rickert, Wiemann, \& Berenson, 2000). African American women who have a long history of abuse are more prone to depression (Kennedy \& Jenkins, 2018; West, 2002). Also, African American women continued to experience depression long after the 
violence relationship was terminated (West, 2002). Whereas, white women reported experiencing decrease depression after their relationship was terminated. Often, African American women who terminate an abusive relationship may place her in a more impoverished status when depending on the partner's income (West, 2002).

\section{Coping with Domestic Violence}

African American women continue to use the SBWA characteristics as a mean of coping with race and gender inequalities (Woods-Giscombé \& Black, 2010). The role of strength is learned and internalizes as an expectable form of cultural coping with passed down from generation to generation. African Americans rely on cultural coping styles in response to stress such as reliance on the extended family and community, religious belief, and spirituality. Racerelated stress events of African American women can contribute to depression (WoodsGiscombe, 2010). However, cultural coping may act as a buffer that protects women from negative psychological race-related stress.

Historically, African Americans have a long history of endurance, survival, and coping in the face of oppression, discrimination, and socioeconomic challenges (Parham, White, \& Ajamu, 1999). Therefore, they often rely on support from family and friends in the time of adversity. These shared experiences of oppression are dominated in this group (Billingsley, 1992, McAdoo, 2007; McAdoo \& Crawford, 1990). African American battered women's mental health-related to their problem-solving focused on coping (e.g., advice to leave or stay with the batterer) contributed to increased symptoms of depression and posttraumatic stress disorder (Kocot \& Goodman, 2003). However, a woman who perceived a high level of support from family and friends have better mental health outcomes (Kocot \& Goodman, 2003). African Americans women subscribe to culturally influence coping patterns such as adherence to (a) longstanding culture of silence, (b) reliance on informal systems of support, and (c) placing the needs of others above their own.

\section{Negative Outcomes/Ineffective Coping}

Increase Stress. Often, African American women who subscribed to the SBWA internalize stress to maintain self-reliance and not seek social support from others (Watson-Singleton, 2017). This image of the SBWA stereotype increases Black women's vulnerability to depressive symptoms associated with stress (Donovan \& West, 2015). Stress and depression have been negatively correlated with self-esteem and happiness (Donovan \& West, 2014). The finding of this research suggested that cultural interventions are needed to reduce this endorsement of the SBWA. The research reported that African American women who internalize the SBWA engage in high effort coping, avoidant coping, postponement of self-care and other maladaptive health behaviors and experience premature health deterioration. African American women are less likely to seek help 
for professional help for abuse, mental health, and physical illnesses in comparison to other racial groups (Woods-Giscombé \& Black, 2010).

Often, African American women internalized their stress suffering quietly as they meet the expectation of others such as families, their jobs, community and even for some the larger society (Barnes, 2017). Rather than seeking help, these women internalized their stress to include experiencing feeling excessive guilt and worthlessness when sacrificing too much of themselves or unrealistic expectations that they and others have placed upon them (Barnes, 2017). Often, they will mask the psychological stress with the appearance of unparalleled strengths.

Lack of Support. Often, African American women who subscribe to the SBWA do not seek assistance or support due to the conscious pressure to remain strong (Kennedy, 2017; Watson Singleton, 2017). The lack of social support contributes to extreme stress impacts on their physical and psychological well-being (Kennedy, 2017; Watson-Singleton, 2017). Typically, the African American women mask their vulnerability and emotionality, preserve through her challenges, resist oppression, maintain power and control, and independently handle her own problems (Davis, 2016). African American women who subscribed to the SBWA internalize stress to maintain selfreliance and not seek social support from others (Watson-Singleton, 2017). Also, African American women who subscribed to the SBWA usually believe that being dependent on others for support places her a risk for being hurt or manipulated (Woods-Giscombe, 2010) and they use selfprotective strategy from mistreatment, disrespect, and pain (Beauboeuf-Lafontant, 2009). Because of their fear of asking and accepting help have left the notion that their survival or success have been left to them.

Cultural Practice. In some cultural practices of African American women, their religious belief and negative views about mental health contribute to them remaining in an unhealthy relationship (Kennedy, 2013). For some, they may remain in the relationship even if the abuse continues. About 1 in every 3 African American women who need mental health treatment received treatment (Jones, 2014). They are more likely to receive religious guidance when working through relationship issues (Jones, 2014; Kennedy, 2013). The perpetrators may be a member of the same congregation with the victims in need of professional mental health treatment placing the victim at risk for harm. In some cases, some congregations' religious beliefs and practices often discourage divorce and promote the forgiveness of the perpetrator. In some cultural practices, their religious beliefs may discourage mental health treatment or just mental health counseling within their congregation. Some congregations may not be prepared to handle the complexity of the situation and deterred the victim in reporting the abuse. In other cases, African American women 
may feel fighting back is the solution than reporting the abuse to the legal system or attending counseling (Kennedy, 2013).

\section{Positive Outcomes/Effective Coping}

Resilience. In mental health, resilience is defined as the process to cope with the challenges in a person's life (Wagnild \& Young, 1993). Resilience is a trait that modifies the detrimental effects of stressors and enhances the process of adaptation and coping with life stressors. The research reported that African Americans who endorsed the Strong Black Women (SBWA) are naturally strong, resilient, self-contained, and self-sacrificing. However, some scholars reported that African American women who subscribed strongly to the Strong Black Woman (SBWA) have significantly higher reports of depression symptoms than those who only mildly embrace the archetype (Donovan \& West, 2015). The research reported the SBWA is associated with poorer psychological outcomes for African American women. These women have a high level of stress. Typically, they do not seek or have an unfavorable attitude toward seeking professional psychological help. However, many African American survivors are resilient to these traumatic experiences because of community activism, spirituality, music, and literature (West, 2002).

Spirituality and Religion. Historically, spirituality and religion have been a critical component of African Americans' lives (Kennedy 2013). Spirituality refers to trust in a greater power that has a positive effect on people (Griffith, Caron, Desrosiers, \& Thibeault, 2007). For Christians, trust is in the power of the true and living God in the Bible. For, secular belief, spirituality is defined as referring to the human experience of discovering meaning, which may or may not include the concept of a personal God (Balmer, VanAsselt, Walker, \& Kennedy, 2012; Rivett \& Street, 2001). Spirituality is often used interchangeably with religion (Bell, Busch, \& Fowler, 2005; Dunn \& Dawes, 1999). Religion, in contrast to spirituality, typically includes institutional affiliations that share a system of beliefs, rituals, and behaviors (Bell et al., 2005; Derezotes, 1995). However, the use of prayer typically overlaps in the conceptualization of both religion and spirituality regardless of organizational affiliation (Bell et al., 1997; Mattis, 2000).

Spirituality and religion help many African Americans draw strength to overcome various forms of adversities such as poverty, illness, rejection, prejudice, and racism (Ennis, Ennis, Durodoye, Ennis-Cole, \& Bolden, 2004). African Americans who use high levels of spirituality reported higher levels of religious coping strategies (Watlington \& Murphy, 2006). Also, African American women of domestic violence with religious involvement reported high levels of social support (Kennedy, 2013; Watlington \& Murphy, 2006). Because of previous traumatic experiences, a person continues to cope with everyday life stressors and negative experiences. 
Victims of domestic violence continue to cope and move beyond this experience (Bonanno, 2004; Tugade \& Fredrickson, 2004).

Spirituality has been reported to lower levels of depression, psychological stress, improve self-esteem, high life satisfaction, and lower levels of alcohol and substance use/abuse and risk-taking behaviors (Ellison, Trinitapoli, Anderson, \& Johnson, 2007). These psychosocial problems are common in victims of domestic violence. Some scholars reported that spirituality has a positive effect over a person overall well-being and alleviating depression (Miller \& Thoresen, 2003; Mystakidou et al., 2008; Phelps, Maciejewski, \& Prigerson, 2009; Reeves \& Reynolds, 2009). Spirituality has been correlated with a higher quality of life (Delgado, 2007).

Spirituality and the use of clergy have been associated with help-seeking and the resilience of African Americans in their attempts to cope with daily events for centuries (Carrington, 2006). Research supported social support has been an essential factor in coping with domestic violence in African American (Coker et al., 2004). Also, religion has been an essential factor in lower suicide rates (Koenig, McCullough, \& Larson, 2001). Spirituality resources have been positively correlated with a sense of harmony and coherence (Simoni, Martone, \& Kerwin, 2002). Also, spirituality is used as empowerment for comfort and relief and coping for African American women (Kennedy, 2013). Also, African American women use spirituality more than African American men.

Faith-based Services. African American women traditionally have a strong connection with faith-based services (Fowler \& Hill, 2004; Potter, 2007). Faith-based leaders can use primary prevention strategies in the use of sermons, biblical teachings, and training (Manetta, Bryant, Cavanaugh, \& Gange, 2003). Other faith-based prevention strategies are teaching and educational resources (Jones \& Fowler, 2009). IPV prevention supportive strategies are often provided by preachers, ministers, and counselors (Nash, \& Hesterberg, 2009). Research indicated that religious involvement correlated with reduced levels of domestic violence and church attendance protects against domestic violence (Ellison et al., 2007). The protective effects of church involvement are strongest for African Americans females.

Empowerment. Empowerment is the process of becoming stronger and more confident, especially in controlling one's life and claiming one's rights (Oxford English Dictionary, 2019). Therefore, empowerment is important in selecting healthy strategies in dealing with domestic violence (Jones, 2014; Kennedy, 2013; Kocot \& Goodman, 2003). Jones (2014) proposed that African American women need to speak out about their domestic violence/intimate partner violence. Sharing of their stories on social media is a helpful strategy in addition, to the use of resources. Kocot and Goodman (2003) suggested that women who receive positive responses from 
sources of help have greater confidence in their abilities to change and leave abusive relationships, and are more likely to access sources of help in the future (Kocot \& Goodman, 2003).

Historically, African Americans have a long history of endurance, survival and coping in the face of oppression, discrimination, and socioeconomic challenge (Kennedy, 2013). Therefore, they often rely on support from family, friends, community, and spirituality in the time of needs. African American females' survivors of IVP frequently experience psychological mental health problems to include depression, anxiety, stress, and somatic complaints (Kennedy, 2013). However, many African American survivors are resilient to these traumatic experiences because of their spirituality. Some African American women stayed in an unhealthy abusive marriage because of cultural and religious beliefs promoting enduring the relationship regardless of the abusiveness. Women who are empowered with a strong spirituality assist her with greater confidence in their ability to change or leave an abusive relationship.

Advocacy. African American women need to be active in forums to change the negative stereotypes of African American females contributing to their domestic violence (Kennedy, 2015). Also, African American women experience more violence at home, school, job, and their neighborhood (Chakara, 2017; Green, 2017). African American women and girls are experiencing more institutional racism because they are disproportionately punished in schools, incarcerated in the criminal justice system after surviving physical and sexual abuse. Recently, African American females and girls are more subjected to racial profiling, police brutality, and incarcerated at a high rate in comparison to other groups (Chakara, 2017; Green, 2017). African American girls at an early age are treated as women in preschool contributing to being handling forceful with law enforcement (Chakara, 2017). Advocacy groups need to work with policymakers to increase awareness and change laws to protect the African American women and females (Jones, 2014; Kennedy, 2015). Stronger laws are needed and advocacy for more treatment options for victims and abusers (Jones, 2014).

\section{Conclusion}

Numerous negative stereotypes have been proposed regarding society's views of African American females. Some of these negative stereotypes have been viewed as contributing to the violence among African American women. Also, economic distresses which affect the African American communities have contributed to African American men's violence toward African American women. In some cases, it is believed that African American women have been protective of the African American men because of the abuse and lynching of slavery thereby accepting intimate partner abuse. However, the younger generation of African American females is believed to becoming just as abusive as the African American male because of psychiatric problems or 
substance abuse and as victims, they are fighting back. Future treatment for victims and perpetrators will be challenging because of these changes in all ethnic groups. The voice of silence is gradually decreasing with the upcoming generation of African American females.

\section{References}

Abrams, J. A., Maxwell, M., Pope, M., \& Belgrave, F. Z. (2014). Carrying the world with the grace of a lady and the grit of a warrior: Deepening our understanding of the 'Strong Black Woman' Schema. Psychology of Women Quarterly,38, 503-518

Africana Voices Against Violence, (2002). Tufts University, Statistics, www.ase.tufts.edu/womenscenter/peace/africana/newsite/statistics.htm.

Amankwaa, L. C. (2003, Spring). Postpartum depression, culture, and African American Women. Journal of Cultural Diversity, 1-2.

Baker, T. A., Buchanan, N. T., Mingo, C. A., Roker, R. \& Brown, C. S. (2015). Reconceptualizing successful aging among black women and the relevance of the Strong Black Woman Archetype. The Gerontologist, 55, 51-57.

Balmer, T.D., VanAsselt, K.W, Walker, C. \& Kennedy, B R. (2012). A phenomenological study of spiritual values in secular-based marriage and family therapists, Journal of Spirituality in Mental Health, 14 (4), 242- 258.

Barnes, Z. (2017). 8 Health conditions that disproportionately affect black women. SELF, 1- 8.

Barnett, O.W. (2000). Why battered women do not leave, part 1. Trauma, Violence, \& Abuse, 1(4), 343-372.

Beauboeuf-Lafontant, T. (2009). Behind the mask of the strong Black woman: Voice and the embodiment of a costly performance. Temple University Press.

Bell, C. C., \& Mattis, J. (2000). The importance of cultural competence in ministering to African American victims of domestic violence. Violence Against Women, 6, 515-533.

Bell, H. \& Busch, N. B. \& Fowler, D.N. (2005). Spirituality and domestic violence Work. Critical Social Work 6 (2), http://www.criticalsocialwork.com.

Bent-Goodley, T. B. (2004). Perceptions of domestic violence: A dialogue with African American women. Health \& Social Work, 29(4), 307-316.

Bent-Goodley, T.B. (2005). Culture and domestic violence: Transforming knowledge development. Journal of Interpersonal Violence, 20, 195-203.

Billingsley, A. (1999). The mighty river: The black church and social reform. New York, NY: Oxford University Press.

Black, A. R., \& Peacock, N. (2011). Pleasing the masses: Messages for daily life management in African American women's popular media sources. American Journal of Public Health, 101(1), 144-150.

Bonanno, G. A. (2004). Loss, Trauma, and human resilience: Have we underestimated the human capacity to thrive after extremely aversive events? American Psychologists, 59(1), 202208.

Bradley R., Schwartz A.C., Kaslow, N.J. (2005). Posttraumatic stress disorder symptoms among low-income, African American women with a history of intimate partner violence and suicidal behaviors: Self-esteem, social support, and religious coping. Journal of Traumatic Stress, 18(6):685-696.

Broussard, P.A. (2013). Black Women's Post-Slavery Silence Syndrome: A twenty- first century remnant of slavery, Jim Crow, and systemic racism--Who will tell her stories? Gender

Race \& Justice, 16: 373

Caetano, R. \& Cunradi, C.B. (2003). Intimate partner violence and depression among Whites, 
Blacks, and Hispanics. Annals of Epidemiology, 13(10), 661-665.

Campbell, R., Wasco, S.M., Ahrens, C. E., Sefl, T., \& Barnes, H. E. (2001). Preventing the "second rape": Rape survivor's experiences with community service providers. Journal of Interpersonal Violence, 16, 1239-1259.

Carrington, C. H. (2006). Clinical depression in African American women: Diagnoses, treatment, and research. Journal of Clinical Psychology, 62(7),779-791.

http://www.cdc.gov/violenceprevention/intimatepartnerviolence/index.html Council.

Chakara, M. (2017). From Preschool to Prison: The Criminalization of Black Girls, Center for American Progress, retrieved from https://www.americanprogress.org/

Coker, A. L., Smith, P.H., Thompson, M. P., McKeown, R. E., Bethea, L, \& Davis, K. E., (2004). Social support protects against the negative effects of partner violence on mental health, CRVAW Faculty Journal Articles. 13.https://uknowledge.uky edu/crvaw_ facpub/113.

Collins, P. H. (2000). Black feminist thought (2nd ed.). Rutledge, New York.

Daly, A., Jennings, J. Beckett, J.O., \& Leashore, B.R. (1995). Effective coping strategies of African Americans. Social Work, 40 (2), 240-248.

Dana, R. H. (2002). Mental health services for African Americans: A cultural/racial perspective. Cultural Diversity and Ethnic Minority Psychology, 8, 3-18.

Davis, A. Y. (1998). Reflections on the Black woman's role in the community of slaves. In J. James (Ed.), The Angela Y. Davis reader (pp. 111-128). Malden, MA: Blackwell.

Davis, S. M. (2016). A partial test of the Strong Black Woman Collective Theory: using structural equation modeling to understand the collective communication practices among Black women groups, Dissertation, University of Iowa.

Delgado, C. (2007). Sense of coherence, spirituality, stress, and quality of life in chronic illness. Journal of Nursing Scholarship, 39: 229-234.

Derezotes, D.S. (1995). Spirituality and religiosity: Neglected factors in social work practice. Arete, 20(1), 1-15.

Donovan, R. A. \& West, L.M. (2015). Stress and mental Health:

Moderating role of the Strong Black Women Stereotype. Journal of Black Psychology, 41, 384-396.

Dunn, A.B., \& Dawes, S.J. (1999). Spirituality-focused genograms: Keys to uncovering spiritual resources in African American families. Journal of Multicultural Counseling and Development, 27(4), 240-254.

Ellison, C.G., Trinitapoli, J.A., Anderson, K.L., \& Johnson, B. R. (2007). Race/ethnicity, religious involvement, and domestic violence. Violence Against Women, 13 (11), 1094-1112.

Ennis, W., Ennis, W. III, Durodoye, B. A., Ennis-Cole, D. \& Bolden, V. L. (2004). Counseling African American clients: Professional counselors and religious institutions. Journal of Humanistic Counseling, 43,197-209. Retrieved October 15, 2007 from http://www.questia.com.

Feagin, J., \& Sikes, M. (1994). Living with racism. Boston: Beacon.

Fischbach, R. L., \& Herbert, B. (1997). Domestic violence and mental health: Correlates and conundrums within and across Cultures. Social Science and Medicine, 45, 1161-1176 http://dx.doi.org/10.1016/S0277-9536(97)00022-1

Fowler, D. \& Hill, H. (2004). Social support and spirituality as culturally relevant factors in coping among African American women survivors of partner abuse. Violence Against Women, 10(11), 1267-1282.

Galanter, M. (2005). Spirituality and the healthy mind: Science, therapy, and the need for personal meaning. New York: Oxford University Press.

Gillum, T. L. (2002). Exploring the link between stereotypic images and intimate partner violence 
in the African American community. Violence Against Women, 8, 64-86.

Gooden, W. E. (1980). The adult development of black men. (Vols 1-2). Ann Arbor, MI University. Green, L. (1999). Stereotypes: Negative Racial Stereotypes and Their Effect on Attitudes Toward African Americans: Perspective on Multiculturalism and culture diversity, Vol. XI, No. 1 Winter 1998-99.

Green, S. (2017). Violence against black women-many types, far reaching effects, Institute for Women Policy Research, retrieved from https://iwpr.org/violence-black-women-manytypes-far-reaching-effects/

Griffith, J., Caron, C. D., Desrosiers, J., \& Thibeault, R. (2007). Defining spirituality and giving meaning to occupation: The perspective of community-dwelling older adults with autonomy loss. The Canadian Journal of Occupational Therapy, 74(2), 78-90.

Hannerz, U. (1969). Soulside: Inquiries into Ghetto Culture. New York: Columbia University Press.

Harris-Lacewell, M. (2001). No place to rest African American political attitudes and the myth of Black women's strength. Women \& Politics, 23(3),1-33.

Huang, C. J., \& Gunn, T. (2001). An Examination of domestic violence in an African American community in North Carolina: Causes and consequences. Journal of Black Studies, 31(6), 790-811.

Jenkins, C.C., \& Kennedy, B.R. (2013). An exploratory study of sexual assertiveness and characteristics of African American women in negotiating condom use at an HBCU.

Journal of Cultural diversity: An Interdisciplinary Journal, 20 (2), 139-145.

Jewell, S.K. (1993). From mammy to miss America and beyond: Cultural images and the shaping of US policy. New York: Routledge.

Jones, A., \& Fowler, T. (2009). A faith community-domestic violence partnership. Social Work and Christianity, 36, 415-429.

Jones, F. (2014). Why black women struggle more with domestic violence. Time

Magazine, retrieved fromhttps://time.com/3313343/ray-rice-black-women-domestic/violence

Kaslow, N. J., Thompson, M. P., Okun, A., Price, A., Young, S., Bender, M., . . Parker, R. (2002). Risk and protective factors for suicidal behavior in abused African American women. Journal of Consulting and Clinical Psychology, 70,311-319

Kennedy, B.K. (2007). Domestic violence: AKA intimate partner violence (IPV). Iuniversi Publication, ISBN 9780595440566.

Kennedy, B.R. (2013). African American Women Christian Survivors of domestic violence

: $\quad$ Running for my life. BRK Healthcare Publications, ISBN-13: 978-0-9897244-6-3.

Kennedy, B.R. (2015). African American Women and domestic violence: empowerment in promoting spirituality for healing (2nd ed.). BRK Healthcare Publications, ISBN13:978-0-9897244-4-9.

Kennedy, B. K. (2017). Intimate partner violence: Promoting the need for adequate screening. assessment and interventions for physical and mental conditions resulting from intimate partner violence. BRK Global Healthcare Journal, 1(1) https://brkhealthcare.com/brkhealthcare-journal/doi10.35455/brk12345

Kennedy, B.R.\& Jenkins, C.C (2018). African American women and depression. Promoting the Need for culturally competent treatment. BRK Global Healthcare Journal, https://brkhealthcare.com/brk-healthcare-journal/ doi:10.35455/brk123456 
Kennedy, B.R., Mathis, C.C. \& Woods, A (2007). African Americans and their distrust of the health care system: Healthcare for diverse population. Journal of Cultural Diversity: An Interdisciplinary Journal, 14, (2), 56-60.

Kocot, T., \& Goodman, L. A. (2003). The roles of coping and social support in battered women's mental health. Violence Against Women, 9, 1-24.

Koenig, H.G., McCullough, M.E., \& Larson, D.B. (2001). Handbook of religion and health. Oxford, New York, NY: Oxford University Press.

Lane S.D., Rubinstein, R.A., Keefe, R.H., Webster, N., Cibula, D.A., Rosenthal, A., Dowdell, J. (2004). Structural violence and racial disparity in HIV transmission. Journal of Health Care for the Poor and Underserved, 15:319-335.

Lee, R., Thompson, \& Mechanic, M. (2002). Intimate partner violence and women of color: A Call for Innovations. American Journal of Public Health, 92 (4), 530-534.

Manetta, A. A., Bryant, D. F., Cavanaugh, T., \& Gange, T. (2003). The church--Does it providesupport for abused women? Differences in the perceptions of battered women and parishioners. Journal of Religion \& Abuse, 5(1), 5-21. doi:10.1300/j154v05n01_02

Mattis, J.S. (1997). Spirituality and religiosity in the lives of black women. African American Research Perspectives, 3 (2), 56-60.

Mattis, J.S. (2000). African American women's definitions of spirituality and religiosity. Journal of Black Psychology, 26 (1), 101-122.

McAdoo, H. P. (2007). Black Families (4th ed.). Thousand Oaks, CA: Sage. McAdoo, H.P. \& Crawford, W. (1990). The black church and family support systems. Prevention in human services, 9 (2) 193-203.

McCollum, V.J.C. (1997). Evolution of the African American family personality: Considerations for family therapy. Journal of Multicultural Counseling \& Development, 25 (3), 219-229.

Miller, W. R., \& Thoresen, C. E. (2003). Spirituality, religion, and health: An emerging field. American Psychologist, 58, 24-35.

Mystakidou, K., Parpa, E., Tsilika, E., Athanasouli, P., et al. (2008). Preparatory grief, psychological distress, and hopelessness in advanced cancer patients. European Journal of Cancer Care 17:145-151.

Nash, S.T., Hesterberg, L. (2009). Biblical framings of and responses to spouse violence in the narratives of abused Christian women. Violence against Women, 15(3), 340-361.

Oxford English Dictionary (2019). Volume 20, Oxford University Press

Parham, T. A., White, J. L., \& Ajamu, A. (1999). The psychology of blacks: An African-centered perspective (3rd ed.). Englewood Cliffs, NJ: Prentice

Phelps, A.C., Maciejewski, P.K., Nilsson, M., Balboni, T.A., Wright, A.A., Paulk M.E., et al (2009). Coping with cancer: Religious coping predicts use of intensive life prolonging care near death. JAMA, 301, 1140 -1147.

Potter, H. (2007). Battered Black women's use of religious services and spirituality for assistance in leaving abusive relationships. Violence Against Women, 13(3), 262-284.

Ramos, B. M., Carlson, B. E., \& McNutt, L.A. (2004). Lifetime abuse, mental health, and African American women. Journal of Family Violence, 19, 153-164.

Reeves, R.R. \& Reynold, M.D. (2009). What is the role of spirituality in mental health? treatment? Journal of Psychosocial Nursing, 47 (3), http://www.psychodyssey.net/wp- $\quad$ content/uploads/2012/05/What-Is-the-Role-ofSpirituality-in-Mental-Health Treatment.pdf

Rickert, V.I., Wiemann, C.M. \& Berenson, A.B. (2000). Ethnic difference in depressive symptomology among young women. Obstetrics \& Gynecology, 95 (1), 55-60. https://doi.org/10.1016/S0029-7844(99)00495-0 
Rivett, M., \& Street, E. (2001). Connections and themes of spirituality in family therapy. Family Process, 40(4), 459-459-67.

Simoni, J. M., \& Cooperman, N. A. (2000). Stressors and strengths among women living with HIV/AIDS in New York City. AIDS Care, 12 (3), 291-297.

Smitherman, G. (Ed.). (1995). African American women speak out on Anita Hill- Clarence Thomas. Detroit, MI: Wayne State University Press.

Staples, R. (1982). Black masculinity. San Francisco, CA: Black Scholar Press.

Thomas, A. J., Witherspoon, K. M., \& Speight, S. L. (2004). Toward the development of the stereotypic roles for Black women scale. Journal of Black Psychology, 30(3), 426-442.

Tidwell, R. (2004). The "no-show" phenomenon and the issue of resistance among African American female patients at an urban health care center. Journal of Mental Health Counseling, 26, 1-12.

Tugade, M. M., \& Fredrickson, B. L. (2004). Resilient individuals use positive emotions to bounce back from negative emotional experiences. Journal of Personality and Social Psychology, 86, 320-333.

Wagnild, G.M., \& Young, H.M. (1993). Development and psychometric evaluation of the resilience scale. Journal of Nursing Management, 1 (2), 165-178.

Watlington, C. G. \& Murphy, C. M. (2006). The role of religion and spirituality among African American survivors of domestic violence. Journal of Clinical Psychology, 62(7), 837857.

Watson, N. N., \& Hunter, C. D. (2015). Anxiety and depression among African American Women: The Costs of strength and negative attitudes toward psychological help-seeking. Cultural Diversity \& Ethnic Minority Psychology. 21(4), 604.

Watson, N. N., \& Hunter, C. D. (2016). "I Had to Be Strong”. Journal of Black Psychology, 42(5), 424-452. http://dx.doi.org/10.1177/0095798415597093

Watson-Singleton, N.N. (2017). Strong black women schema and psychological distress: The mediating role of perceived emotional support. Journal of Black Psychology, 43(8), 778788. http://dx.doi.org/10.1177/0095798417732414

West, C.M. (2002). Battered, Black, and Blue: An overview of violence in the lives of black women. Women \& Therapy, 25 (3/4), 5-27.

West, C. M. (2004). Black women and intimate partner violence: New directions for research. Journal of Interpersonal Violence, 19 (12), 1487-1493.

Willis, J.T. (1989). Some destructive elements in the African American community. Family Therapy, 17 (2), 139-147.

Woods-Giscombé, C. L. (2010). Superwoman schema: African American women's views on stress, strength, and health. Qualitative Health Research, 20(5), 668-683.

Woods, K. C. (2013). The strong Black woman archetype and intentions to seek therapy for depression: A cultural application of the theory of planned behavior (Doctoral dissertation, MICHIGAN STATE UNIVERSITY).

Wyckoff, R., \& Simpson, S. (2008). The effects of self-protective behaviors on injury for African American women in domestic violence situations. Crime, Law and Social Change, 49 (4), 271-288.

Bernice Roberts Kennedy, PhD, APRN, PMH-CNS, BC, is a research consultant at BRK Global Healthcare Consulting Firm, LLC, P.O. 90899, Columbia, South Carolina, 29290. Dr. Kennedy may be reached at: brkhealthcare@gmail.com 
